\title{
El enfoque de análisis de los issues: el caso de la educación en las narraciones de la esfera pública mediatizada
}

\author{
Marina MANTINI* \\ marina.mantini@gmail.com
}

(Abstracts y palabras clave al final del artículo)
Enviado: 20 de abril de 2013
Evaluado: 24 de junio de 2013
Aceptado: 19 de julio de 2013

Las transformaciones actuales en la producción, circulación y recepción de la información están cambiando las características del espacio público, tal y como habían sido analizadas por los estudios tradicionales (Arendt, 1974; Habermas, 1989; Dewey, 2004). Cómo los asuntos públicos aparecen en los medios, circulan, se transforman y desaparecen, son dinámicas hoy en día difíciles de entender en su complejidad. La investigación que proponemos aquí nace de esta exigencia de indagar el papel de los medios de información, con la actual incorporación de los recursos onli$n e$, en la conformación de la esfera pública mediatizada (EPM).

El objetivo de este artículo es analizar los elementos que construyen mediáticamente los issues (o asuntos relevantes), definiendo el issue como un asunto que suscita controversia pública, alrededor del cual se genera un conflicto entre distintos actores que, de una manera u otra, están involucrados en él y luchan en la arena mediática para impulsar sus intereses, valores y perspectivas.

Nuestro enfoque sobre el issue es por lo tanto distinto de teorías como la de la agenda setting (McCombs, 1985; 1996), la agenda building (Lang y Lang, 1981) y la teoría del framing (Entman, 1993; Weaver y Eliott, 1985), que consideran el issue como un objeto que se define y delimita con anterioridad respecto a su posicionamiento en el espacio público. Estos estudios además se suelen catalogar entre los estudios de audiencia y los dedicados a los efectos sociales y psicológicos de los medios de comunicación de masas (Wolf, 1992) -a menudo cercanos a los estudios cognitivistas. A diferencia de estos enfoques, exploraremos aquí un punto de vista constructivista y performativo en el estudio de los medios de información, interesado en la producción

* Semióloga en Baba, investigación de mercado y tendencias. Milán.

${ }^{1}$ Según la teoría del framing, los periodistas enfocan la realidad proporcionando al público una manera de interpretar los hechos, así como el priming es el proceso por el cual una información se prioriza en el juicio. Framing y priming están relacionados con el segundo nivel de la agenda setting, según el cual no sólo los mass media proponen los temas de atención a la sociedad (primer nivel), sino también las percepciones cognitivas sobre estos temas. 
de sentido de la información. Si, como señalaba Tuchmann (1999), las noticias contribuyen a construir la realidad, entendemos que cualquier forma de comunicación no sólo representa, sino que funda el mismo objeto del intercambio comunicativo. Nuestra cuestión central es esa construcción del objeto de la comunicación, el issue, en las prácticas informativas. En ellas el issue toma una forma discursiva, que indagaremos desde un punto de vista narrativo y enunciacional, dialógico. La composición del issue es polifónica, y conflictiva: un asunto es siempre controvertido, pues en él confluyen perspectivas diferentes y hasta contrapuestas, lo que concuerda con la concepción de la democracia deliberativa de Hannah Arendt. En esta línea, Marres (2005) sostiene que no existen asuntos que no sean conflictivos.

Para el estudio de caso, hemos elegido el issue y las noticias sobre las reformas del sistema educativo en España, en particular las protestas llevadas a cabo por parte de varios colectivos (padres, profesores y estudiantes, además de organizaciones como sindicatos, partidos, plataformas ciudadanas), conocidas a nivel mediático como la "marea verde", en contra del gobierno del Partido Popular y especialmente del ministro de Educación, Cultura y Deporte, José Ignacio Wert.

Nuestro corpus de análisis está formado por los artículos sobre estas protestas publicados por El País y El Mundo, en sus páginas web (elpais.com y elmundo.es) y en sus ediciones impresas, junto a otras noticias publicadas en otros medios temáticos de información online (blogs, plataformas, otros sitios web de información sobre educación de los que los más visitados son Soy Pública http://soypublica. wordpress.com/ y Yo estudié en la pública http://www.yoestudieenlapublica. org/video.php), que nos permitían dar cuenta de las distintas perspectivas propuestas por los actores involucrados. Tras identificar los sujetos, los actores que participan en la definición y desarrollo del issue, hemos analizado, usando una metodología socio-semiótica, sus perspectivas y marcos de sentido, siguiendo los discursos y las narraciones que, al tiempo que proporcionan una interpretación del conflicto, contribuyen a modificar el mismo issue en la EPM.

Esto nos lleva inevitablemente a cruzar el debate sobre las transformaciones del periodismo, la "crisis" de la prensa y los retos a los que se enfrenta el "hacer periodístico" hoy en día. Aunque en este artículo no desarrollaremos el tema de las prácticas de información y de las rutinas productivas ${ }^{2}$, al centrarnos en las narraciones en los sitios web analizados, es inevitable tener en cuenta la encrucijada en la que se encuentran actualmente, debido a las profundas transformaciones en curso, que forman un terreno muy resbaladizo tanto para los estudios académicos como para las aplicaciones profesionales.

A lo largo de la investigación hemos leído y estudiado los artículos publicados por El País y El Mundo sobre el "conflicto en educación" desde abril hasta diciem-

2 La investigación completa, sin embargo, utilizando un doble marco teórico y metodológico que cruza los análisis semióticos con la etnografía (observación participante, observación participante online, entrevistas en profundidad y trabajo de campo de documentación), hace hincapié justamente en las prácticas de información y en el periodismo contemporáneo. Uno de los objetivos es analizar cómo los productores de información sobre un issue concreto (periodistas, activistas, blogueros, community managers) contribuyan, con sus rutinas diarias (que se están trasformando tanto por los cambios tecnológicos como por los empresariales, los de los usuarios y del mercado) y su labor periodística, a las modificaciones de la esfera pública mediatizada. 
bre de 2012, además de otras noticias publicadas en las plataformas que hemos mencionado arriba. Sin embargo, en este texto mostraremos el análisis de dos artículos, uno publicado en elpaís.com y el otro en elmundo.es sobre la jornada de huelga en educación convocada, por primera vez en la historia de España, por la Confederación Española de Asociaciones de Padres y Madres de Alumnos (CEAPA) de los colegios e institutos públicos del 18 de octubre de 2012. A partir del análisis comparado de los dos textos, expondremos nuestras conclusiones sobre los relatos prevalentes en la EPM sobre las reformas en educación y las perspectivas conflictivas que evidencian las distintas narraciones que circulan en la misma. Así, podremos formular hipótesis también sobre los marcos de sentido propuestos por los dos periódicos online.

\section{CONTEXTO Y ANTECEDENTES TEÓRICOS}

Entendemos la esfera pública en relación con los medios de información, como un espacio público, abierto, para el conocimiento y deliberación sobre los asuntos comunes en el que son fundamentales los medios de comunicación (Peñamarín, 2008), por lo que hablamos aquí de esfera pública mediatizada (EPM). Por un lado, la difusión masiva de las tecnologías de la información y comunicación, así como los cambios empresariales de las industrias culturales (Fenton, 2010; Curran, 2012; Díaz Nosty, 2011; De la Sierra et al., 2010) han modificado profundamente la prensa y el periodismo. Al mismo tiempo, Internet, como tecnología, con prácticas culturales y comunicativas novedosas, ha añadido una ulterior complejidad al espacio de intercambio, representación y estructuración de la sociedad, multiplicando y potenciando las posibilidades de acción y de interacción (Dahlgren, 2005).

En Europa y en España, la reflexión se ha centrado, por un lado en los cambios estratégicos a los que se está enfrentando la prensa en el mercado de la información, debido a su excesiva mercantilización y a la falta de recursos (Curran y Witschge, 2010: 116; Freedman, 2010: 35-50; Reig, 2011). Por otro lado, se discute sobre los modelos de periodismo, el hacer periodístico, la cultura profesional del periodista y su misma conceptualización (McChesney, 2012; Curran, 2010; Diezandhino, 2012). Igualmente, se están afianzando tesis según las cuales los valores del periodismo están siendo también (y cada vez más) afectados por las condiciones laborales de los profesionales (Cáceres Zapatero, 2011; López Hidalgo y Mellado Ruiz, 2006; APM, 2012). Las rutinas productivas, a consecuencia de los cambios laborales y empresariales, están a su vez condicionadas por las transformaciones estructurales del mercado de la comunicación, debido a las fusiones de los distintos grupos en grandes multinacionales (y los consecuentes oligopolios a nivel global, Reig, 2011) y debido también a las políticas de comunicación implementadas a nivel local y europeo (De la Sierra y Mantini, 2011), abocadas a los valores neoliberales del mercado más que a perseguir los principios democráticos de la libertad de expresión e información, pluralismo y participación; y finalmente también a los hábitos y prácticas de consumo de los usuarios de la comunicación (Boczkowski y Peer, 2011; Gillmor, 2008; Mezza, 2011). 
Es imprescindible por lo tanto tener en cuenta todos estos elementos a la hora de emprender el estudio en el ámbito de la información online. Sin tampoco sobrevalorar el papel de Internet, porque si es innegable que ha transformado profundamente las prácticas periodísticas, así como la producción, la circulación y la recepción de la información, no obstante la prensa sigue siendo influyente, sea en soporte papel o digital. Consideramos relevante el estudio de los casos de El País y El Mundo, en sus versiones digitales, porque hoy en día son dos cabeceras claramente influyentes en España (ver AIMC, 2012).

\section{MARCO TEÓRICO Y METODOLÓGICO}

Hemos empezado este artículo a partir de la definición de "asunto" (issue), que coincide con el punto de llegada de la teoría de la agenda setting. Nosotros partimos de la constatación de la existencia de asuntos conflictivos en la agenda mediática, puesto que nos interesa estudiar las dinámicas a través de las cuales los distintos actores intentan hacer valer su perspectiva como valiosa y aceptable (endorsable) desde el punto de vista del interés general (Krause, 2008). Desde el enfoque que proponemos, el issue se define como lugar de encuentro y confrontación de las perspectivas de los sujetos sobre él. A través de la representación mediática de las perspectivas de los distintos actores se negocia en los textos la interpretación y significación del issue.

Para dar cuenta de las perspectivas que constituyen la trama discursiva del issue "reformas en educación", analizaremos los discursos de los actores interesados en este asunto. Un actor político (sujeto) trata de definir un objeto de valor (en el sentido de la narratividad de Greimas, 1979), en el proceso de hacer de ello un issue público. Este proceso conlleva la acción del sujeto en dos planos. La construcción de su discurso y perspectiva sobre el asunto (en asociaciones, reuniones, asambleas, manifestaciones) y el intento de introducir su perspectiva y hacerla relevante en la esfera pública mediatizada, en la cual el actor trata de lograr su transformación en un objeto de valor discursivamente integrado entre los intereses públicos.

El actor será introducido como sujeto político (pero también semiótico y comunicativo) en el espacio mediático de los medios de información a través de una perspectiva, concebida como visión, definición, figurativización del asunto en cuestión y por tanto del conflicto que implica. Tratará de que esa perspectiva sea incluida (junto con las otras existentes) en la narración que los medios construirán sobre el issue en cuestión.

En el texto mediático (compuesto por piezas sucesivas y, especialmente en los medios online, que contienen diferentes entradas, comentarios, links, etc.), el asunto aparece en constante de-construcción y re-construcción, iluminado por el encuentro y desencuentro entre los sistemas de sentido de los sujetos que intervienen como voces cualificadas para la definición y caracterización del asunto. Pero este rasgo es aplicable a toda enunciación, pues, como escribía Ferdinand de Saussure, "Il nous est interdit en linguistique, quoique nous ne cessions de le faire, de parler 'd'une chose' a differents points de vue, ou d'une chose en général, parce que c'est le point 
de vue qui seul FAIT la chose" (Saussure, 2002: 201 en Peñamarín, 2011). Para la socio-semiótica, en los textos hay siempre una dimensión polémica donde se manifiesta la diversidad de perspectivas, tanto en el nivel de los actores o voces representadas, como en el nivel de la enunciación, como ha sido estudiado, por ejemplo en la comunicación mediada por los periódicos (Lorusso y Violi, 2005: 83-85).

Entendemos por perspectiva la visión o la concepción que posee un sujeto de un objeto de valor, el issue de la educación, en nuestro caso. Esta relación cognitiva y valorativa motiva la acción del sujeto de cara a lograr su objetivo, configurando así el relato de su éxito o fracaso (en este sentido, para la semiótica, la dimensión narrativa está inscrita en todo texto). Por ejemplo, el movimiento LGTB definió como uno de sus objetivos la legalización del matrimonio homosexual. Esta perspectiva entró en conflicto con las visiones dominantes del matrimonio, pese a lo cual, finalmente logró su objetivo en algunos lugares, escribiendo un relato de triunfo, y se está imponiendo en otros. La perspectiva se distingue del punto de vista porque la primera es determinada por la historia que se elige contar, mientras el punto de vista pertenece a quien interpreta la historia (Lorusso y Violi, 2004: 115), pero ambas tienen una triple dimensión: perceptiva, cognitiva y valorativa (Casetti y Di Chio, 1991). Estos conceptos guiarán el análisis que proponemos del modo en que las distintas piezas conforman el asunto conflicto en la educación en España.

Nuestros análisis pretenden entonces presentar unas respuestas plausibles a las siguientes preguntas: ¿el periódico privilegia un marco de sentido?, ¿este corresponde a la perspectiva de una de las partes?, ¿presenta las diferentes perspectivas en conflicto?; ¿excluye alguna de ellas?, ¿expresa los intereses y valores de los varios actores, los justifica, valoriza o degrada?, ¿contribuye a la deliberación pública a través de la confrontación de los distintos puntos de vista, en búsqueda de intereses o valores comunes o, al contrario, privilegia los discursos hegemónicos y la falta de discusión pública? (Mouffe, 2007).

\section{OBJETO DE LA INVESTIGACIÓN Y JUSTIFICACIÓN}

Hemos elegido como objeto específico de análisis los sitios web de El País y El Mundo, considerando que las plataformas online se diferencian del periódico impreso y digital en cuanto son plataformas de información interactiva, de acceso universal y gratuito, con puntos de contacto y diferencias respecto de los otros formatos. Además, El Mundo y El País, debido a sus estructuras empresariales, siguen lógicas editoriales y estrategias comerciales distintas para los varios soportes.

El asunto elegido, por su importancia, relevancia y durabilidad en la escena pública, ha sido la reforma de las políticas educativas, establecida en primera instancia con el decreto ley del gobierno del 20 de abril de 2012. Siguiendo el asunto a lo largo del tiempo, hemos destacado cuatro hitos en el conflicto en educación, coincidentes con cuatro eventos:

- la huelga general de todos los niveles educativos del 22 de mayo de 2012;

- la publicación del anteproyecto de LOMCE - Ley Orgánica para la mejora de la calidad educativa, el 25 de septiembre de 2012; 

2012;

— la huelga conjunta de estudiantes, padres y madres del 18 de octubre de

- la huelga general del 14 de noviembre de 2012.

Todos estos momentos han supuesto una exaltación del conflicto y han generado una gran cobertura mediática sobre el issue de la educación, que ha circulado a lo largo y ancho en la EPM. Específicamente, hemos hecho confluir el análisis semiótico de los textos publicados sobre la huelga del 18 de octubre de 2012, un total de 18 artículos entre elpais.com y elmundo.es, en la semana de "lucha". Aquí presentaremos dos de ellos como ejemplificación de los análisis realizados y de los resultados, añadiendo algunas consideraciones más amplias referidas a la investigación general.

\section{ANÁLISIS COMPARADO DE LOS DOS ARTÍCULOS QUE CIERRAN EL DÍA DE HUELGA DEL 18 DE OCTUBRE DE 2012}

Como hemos adelantado, siguiendo la tradición estructuralista y greimasiana, hemos realizado un recorrido de análisis de la superficie a niveles más profundos de la narración, incluyendo también los aspectos paratextuales (Genette, 1987) e intertextuales (Kristeva, 1978) aplicados a los medios online, con especial atención a la estructura hipertextual de los sitios web (Cosenza, 2005). No consideramos pertinente entrar aquí en una discusión sobre la interactividad (o el simulacro de ella, cfr. Mantini, 2012; Manetti, 2008) de los sitios web, pero tendremos en cuenta que, en el dispositivo enunciativo de un hipertexto como el "artículo online", la competencia y la capacidad performativa del lector/usuario que activa diferentes links dan origen a narrativas transmediales (Jenkins, 2003).

Los artículos que analizamos aquí han sido publicados por las webs de El País y El Mundo, respectivamente a las 22,13 y a las 19,46 horas del día de la jornada de huelga del 18 de octubre de 2012. Hemos elegido estos dos textos para poder comparar textos de género y tipología lo más similares posible, además por ser ejemplificadores de los marcos de sentido utilizados.

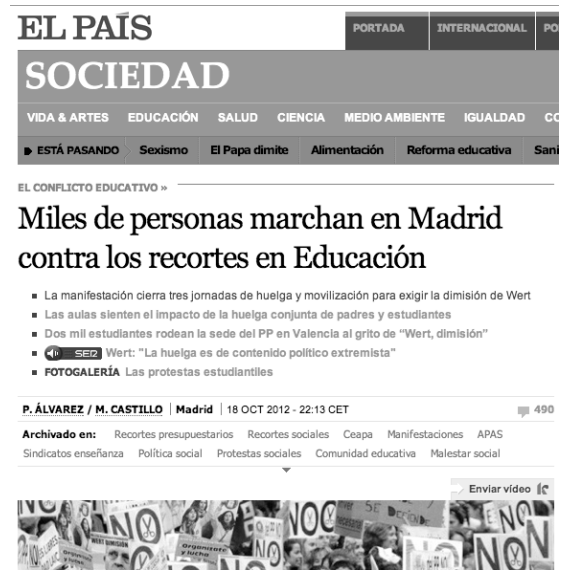

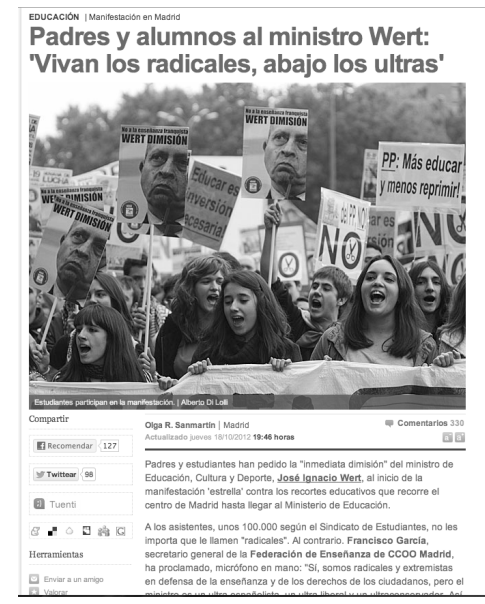

CIC Cuadernos de Información y Comunicación 2014, vol. 19 233-251 


\section{1. "MILES DE PERSONAS MARCHAN EN MADRID CONTRA LOS RECOR TES EN EDUCACIÓN" (WWW.ELPAIS.COM)}

Empezaremos por sintetizar separada y brevemente los puntos salientes del análisis de cada artículo, mientras en la descripción de los resultados ampliaremos la comparación de los marcos y las narraciones de los dos periódicos.

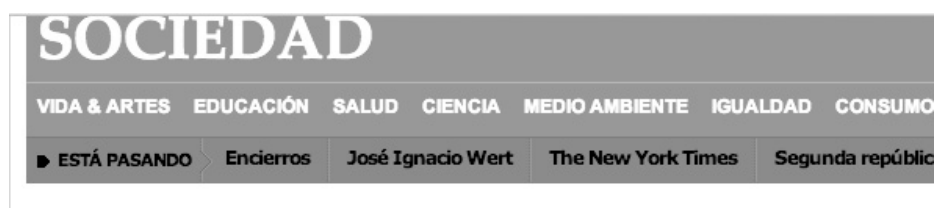

EL. CONFLICTO EDUCATIVO

\section{Miles de personas marchan en Madrid contra los recortes en Educación}

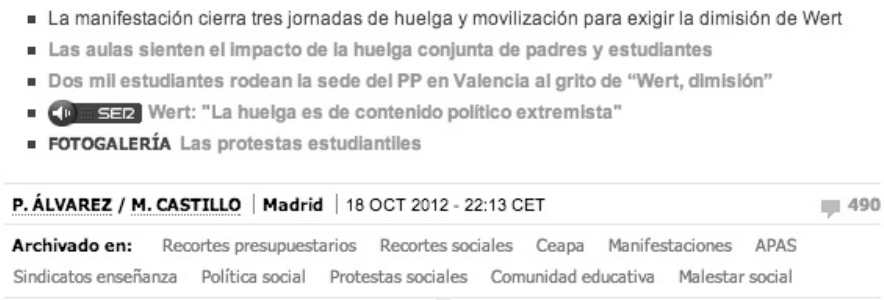

La estructura de la web de El País está organizada por secciones como cualquier periódico en papel, en este caso la etiqueta nos señala que estamos en Sociedad, mientras el artículo es almacenado en la sección especial (donde están recopilados temáticamente todos los artículos sobre educación, no sólo políticos) a la que se accede clicando en el antetítulo el conflicto educativo.

Como es de esperar de un hipertexto, hay varios elementos paratextuales a los que se hace referencia: las secciones del periódico (educación como etiqueta espacial que sitúa el artículo en la web, y recortes en educación que enlaza con los artículos similares, guiando ya al lector en una dirección concreta de interpretación); los otros artículos utilizados como subtítulos ("Las aulas sienten el impacto de la huelga conjunta de padres y estudiantes" y "Dos mil estudiantes rodean la sede del PP en Valencia al grito de "Wert, dimisión"'); la foto galería de las manifestaciones y de la huelga; los videos; el audio de una entrevista de Wert a la cadena Ser ("Wert: 'La huelga es de contenido político extremista"'). Estos elementos para e hyper textuales nos proporcionan unas huellas enunciativas que nos llevan a establecer conexiones de sentido: se prefigura una contraposición Wert-sociedad (en los tags se reitera mucho el adjetivo "social"), mientras título, subtítulo y la foto de portada instauran un marco de conflicto.

La multimodalidad que suele caracterizar la interfaz web (Manovich, 2005) en este caso es doble: abriendo la página web, nos encontramos con la imagen de una manifestación que, a segunda vista, es la instantánea de un video-reportaje sobre la manifestación. 


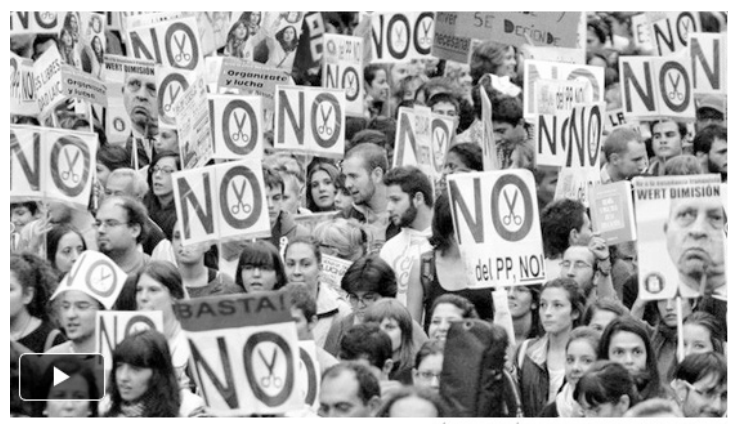

En la imagen se muestra una multitud de gente que lleva el conocido cartel (el NO con el dibujo de unas tijeras para significar "recortes") que forma parte del imaginario colectivo español, presente en todas las manifestaciones contrarias a las varias reformas del gobierno del PP. En esta instantánea en concreto es el cartel que lleva la mayoría de los retratados, aparte de uno en primer plano a la derecha (según la dirección visual del lector frente a la pantalla) y casi fuera del marco, con una foto de Wert (muy conocida y poco favorecedora), con el ceño fruncido, la boca hacia abajo y el texto "Wert dimisión". Sin entrar demasiado en el detalle del análisis fotográfico, la imagen reenvía a la "marcha" de oposición de miles de personas del titular, presentando una multitud compacta y homogénea con casi idénticos carteles.

Si pulsamos, comienza el video reportaje (de Maryem Castillo, coautora del artículo junto a Pilar Álvarez) realizado por El País (País Live), donde se entrevista a los manifestantes que añaden perspectivas con respecto al texto escrito: una maestra introduce la cuestión del ataque a los profesores de los colegios públicos (aumento de ratio de alumnos, falta de maestras de apoyo para niños con problemas) por parte del Gobierno; se ven y escuchan estudiantes coreando "la uni no se vende se defiende".

Como hemos notado en el paratexto, la presentación de las múltiples voces de este reportaje contribuye a la construcción del relato de este medio del sujeto protagonista "sociedad" que protesta por los recortes. El enmarcado del issue (reformas de las políticas educativas) es el de "conflicto" en educación. En las noticias relacionadas, sección abajo, continúa la estrategia señalada: se insertan otras voces con perspectivas confluyentes (las protestas universitarias; la cuestión de la inmersión lingüística, problema que surge con la LOMCE la propuesta de Ley Orgánica para la Mejora de la Calidad Enunciativa, que confiere más peso a la enseñanza del castellano frente a la "inmersión" en catalán, etc.).

Entrando en el cuerpo central del artículo, observamos el uso mayoritario de los discursos directos, con citas entre comillas. El artículo empieza con la frase "de lo general a lo particular", donde el enunciador nos propone un punto de vista, que sin embargo parece más adecuado al estilo del texto "de lo particular a lo general", ya que empieza con historias personales (testimonios de personas identificadas con nombres, edad, trabajos, que tienden a dar un cuadro de la sociedad española); se resalta la dimensión afectiva (las relaciones familiares: la nieta, los abuelos, madres e hijos; el estudiante en dificultades económicas para pagar sus estudios); se hace hincapié en la situación conflictiva ("Más de 100.000 personas, según los convo- 
cantes; (la Delegación del Gobierno no ha ofrecido cifras"), se desarrolla la metáfora bélica ("si no hay solución habrá revolución"; los gritos, los cantos).

Este artículo nos proporciona una representación de un conflicto muy dramático y grave entre la sociedad y el gobierno, personalizado en Wert. Entre los locutores citados, José Luis Pazos de CEAPA y Tohil Delgado del Sindicato de Estudiantes (convocantes de las protestas) utilizan palabras contundentes: la reforma es una "contrarreforma"; al ministro se le considera en "funciones". Wert mismo, introducido como polémico locutor directo desde el subtítulo, habla de "contenido político extremista". El tambor (¿de guerra?) y la canción citados en el final ("a galopar a galopar hasta enterrarlos en la mar") también sugieren un escenario de guerra.

La narración por otra parte exalta la creatividad de los estudiantes, usa imágenes llamativas (la poesía de Alberti; la frase final "de fondo suena un tambor"), cita los lemas de la protesta más compartidos (y compartibles) "Por la educación pública. Por el futuro de nuestros jóvenes"; los detalles destellan ternura y afectividad (el bebé envuelto en una tela; la mano de la niña María, etc.) y los manifestantes están muy lejos de los "radicales antisistema".

La estructura y el registro del artículo respetan las reglas del género información: se ofrecen muchos datos e informaciones añadidas (vehiculadas por los recursos multimedia, enlaces, casi todos internos a elpais.com, y videos), en la óptica de "construcción de la objetividad" (Tuchmann, 1999). Sin embargo, los dispositivos enunciativos inciden en las "historias de vida" (las familias que acuden enteras; la madre cuyo marido es profe en la pública y también le han rebajado el sueldo; los jóvenes que no saben cómo pagar la universidad y tienen que trabajar duro; los abuelos preocupados por el futuro de los nietos), en las dificultades, recogiendo las voces en contra de las reformas (no citadas como reformas sino como "recortes") más propias de un artículo de sociedad o reportaje: todas condenan la que, se insinúa, es una reforma política ("Que no digan de forma peyorativa que esto es una manifestación política porque todo lo es. Esto y el recorte también"). Se entrevista a dos estudiantes universitarios que llevan banderas republicanas, sugiriendo otro conflicto, político e ideológico, entre monarquía y república, que reenvía a un eje de valores profundos opuestos, los privilegios en contra de la igualdad ("la escuela pública de tod@s para tod@s").

Las periodistas aquí asumen la enunciación por el periódico, como enunciadores delegados (Lorusso y Violi, 2004: 60), y su línea editorial, que generalmente etiqueta las protestas en el ámbito de la educación como un conflicto muy grave entre la sociedad y el gobierno, singularizado por el ministro Wert. El País en sus artículos sobre el issue suele reiterar las causas de las protestas, haciendo suyas las perspectivas sustentadas por varios de los colectivos opositores organizados (como por ejemplo la FAPA, Federación de la Comunidad de Madrid de Asociaciones de Padres y Madres del Alumnado, Francisco Giner de los Ríos, las Plataformas Soy Pública o Yo estudié en la pública, aunque generalmente no son explicitadas como fuentes), una línea que encontramos a lo largo del año en los artículos de este periódico, tanto en su edición online como en la impresa (y especialmente de artículos de opinión). En este artículo en particular, se asumen los argumentos y las perspectivas de los padres y los estudiantes, representados por la CEAPA y el Sindicato de 
Estudiantes, mientras no se explicitan otros sujetos (como los recordados arriba, la FAPA o las plataformas ciudadanas) que sin embargo comparten (y amplían) estas mismas perspectivas.

Pasando a analizar la función del enunciatario del relato del enfrentamiento entre la sociedad española y el ministro de Educación, nos parece que se identifica con la misma sociedad española, en su conjunto, y, en segundo lugar, con el lector modelo del El País (progresista y de una izquierda moderada) así como con los participantes de la manifestación, cuyas razones son ampliamente reflejadas por este artículo y sobre todo en el relato general que se desarrolla (con otros artículos y en otros medios pertenecientes al grupo). Encontramos además huellas enunciativas que construyen un enunciatario participativo, interactivo (hay muchos comentarios y una amplia difusión en las redes sociales, pese a la hora tardía de publicación). En otro nivel, otro enunciatario de la narración es Wert, al que se dirigen gran parte de las reivindicaciones de los locutores citados en el texto, y es destinatario directo de las protestas y blanco de insultos y consignas (se pide su dimisión, confiriendo a la narración un fuerte carácter performativo y explicitando el "deber hacer" que se requiere a Wert, para reparar al daño hecho a la sociedad española). Se presenta su perspectiva de forma directa, con el enlace a la entrevista en la que tacha a los padres de extremistas y de estar manipulados por organizaciones e ideologías políticas de izquierda, o también indirecta y polémicamente por boca de una madre.

En síntesis, este artículo de elpais.com nos propone una perspectiva homogénea y coherente, a la que contribuyen diferentes voces y puntos de vista, sobre las reformas en educación, definido como un conflicto entre ideologías (la de la igualdad frente a la del privilegio) y como una guerra que contrapone la sociedad española en su totalidad con el ministro Wert, cuyo objetivo es desmantelar la escuela pública y que aparece como indiferente a las dificultades y las circunstancias dramáticas de los sujetos que sufren las consecuencias de sus decisiones.

\section{2. "PADRES Y ALUMNOS AL MINISTRO WERT: 'VIVAN LOS RADICALES, ABAJO LOS ULTRAS"” (WWW.ELMUNDO.ES)}

En el caso de elmundo.es el artículo publicado, más corto y menos exhaustivo que el de El País, es introducido por un titular más llamativo y agresivo, con una imagen en primerísimo plano inmediatamente después. Leyendo por primera vez el texto, salta a la vista el uso de un registro de teletipo, nota de prensa, de información básica, rápida y esencial. 


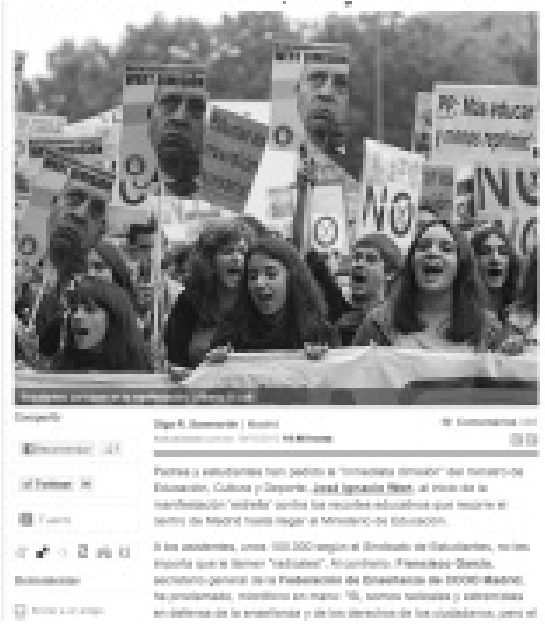

Se confiere más relevancia a los recursos multimedia (fotos y videos) e interactivos (más redes sociales, aunque el tráfico que generan es bajo; más acciones posibles para el usuario). Hay menos artículos relacionados, mientras la distribución espacial y la construcción enunciativa visual confirman un registro y un género de nota de prensa, noticia breve. La periodista es identificada con su nombre (ni foto ni twitter), hay menos intervención del enunciador y una total coincidencia con la línea de El Mundo.

El titular, sin embargo, contrasta por ser más llamativo y "conflictivo".

Se refiere (de forma no tan inmediata) a una narración transmediática sobre el issue que supera los limites del artículo para adquirir sentido a través de otras noticias y otros medios. "Vivan los radicales, abajo los ultras" es una frase pronunciada por un sindicalista de Comisiones Obreras durante la manifestación en Madrid, en respuesta diferida a las declaraciones de Wert de los días anteriores (llamando radicales a los opositores en la entrevista radiofónica citada arriba). La foto es focalizada sobre tres jóvenes, que aunque parecen corear consignas están sonrientes, sujetando una pancarta ante una multitud que permanece al fondo, esfumada, mientras el ángulo visual es más estrecho y personal. La posición de la imagen, inmediatamente después del titular, vincula estrechamente el sentido entre ambos. Los estudiantes son más jóvenes, claramente "alumnos", con respecto a los "padres" del titular, pero hay cierto contraste con la aserción porque la foto no genera tanto una sensación de radicalidad, como de lucha juvenil.

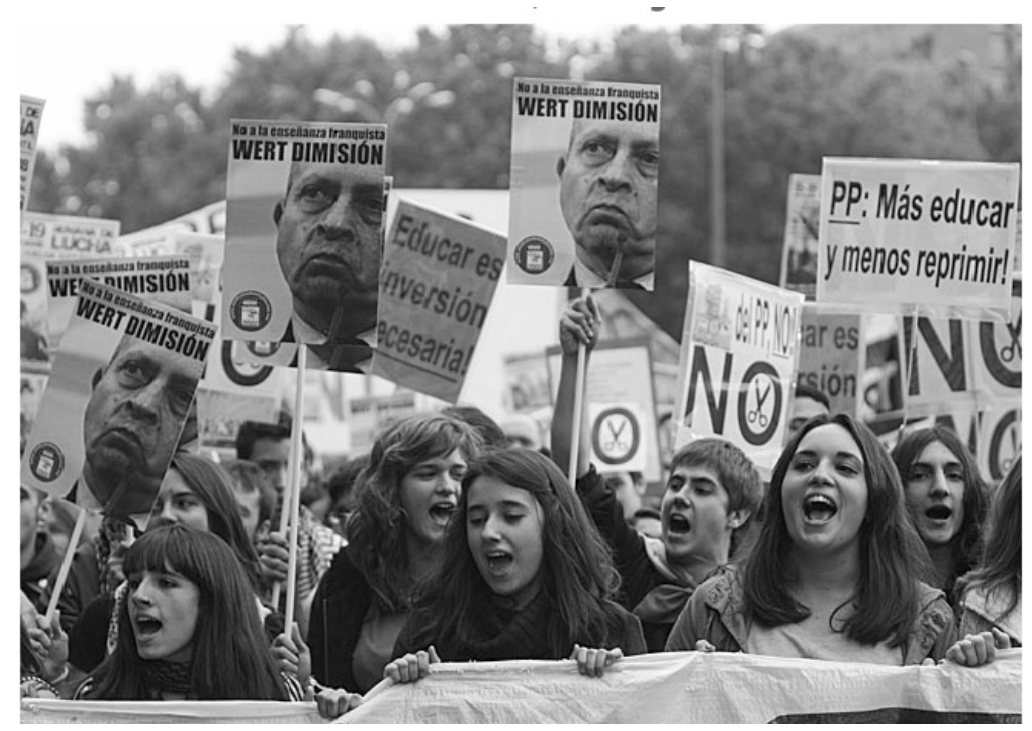


Hay cierto contraste ${ }^{3}$ de estilo entre el texto y el paratexto: la narración impersonal, que en el primer párrafo resume concisamente las $5 \mathrm{~W}$ del buen periodista, las citas y los distintos locutores que expresan su opinión con el discurso directo, dentro del texto, son opuestas al extremismo y la subjetividad expresadas por el titular y la imagen.

Aunque se siga haciendo hincapié en el conflicto, su representación es distinta a la de El País: la narración se centra en un enfrentamiento entre actores políticos, el Partido Popular, Izquierda Unida, los sindicatos ${ }^{4}$. Se sugiere sutilmente la asimilación de la perspectiva de la CEAPA y de los padres y los estudiantes a la de los sindicatos y a IU (en coincidencia con la perspectiva explicitada por el ministro Wert). El conflicto aparece más politizado que ideologizado. Se atribuyen los aspectos de la radicalidad y del extremismo a ciertas posiciones políticas. Se introducen distintos locutores directos que claman contra el PP ("huelgas, manifestaciones, encierros e infinidad de asambleas para protestar por la política educativa del PP") y no contra el gobierno, mientras se da amplio espacio a exponentes de partidos y sindicatos, con nombres y apellidos (Cayo Lara, Francisco García, etc.), imposibilitando la identificación con la sociedad española que sugería El País.

Al mismo tiempo, Wert sigue siendo el blanco de las protestas ("inmediata dimisión"; los carteles en primer plano con la cara "poco favorecedora" que hemos visto), con la diferencia de que se presenta como un enfrentamiento entre este y organizaciones concretas, los sindicatos ("presencia física -no solo moral- de los sindicatos. UGT, CCOO y STES están aquí") y los colectivos de profesores. Se relata la excepcionalidad de la huelga (un insistir continuo ${ }^{5}$ sobre "es la primera vez en la historia de España") pero al mismo tiempo se conecta con la rutina de otras huelgas, de las que convocan habitualmente los sindicatos que, se subraya, "están aquí", situándola en un escenario de confrontación política donde cada uno cumple con su función habitual, lo que tendría el efecto de minimizar la extensión social de la protesta.

\footnotetext{
${ }^{3}$ Recurriendo a nuestro conocimiento del contexto, esta disconformidad puede tener que ver con que la periodista redacta el texto central, por telefóno, pero muchas veces el titular y la foto los pone la redacción El Mundo web.

${ }^{4}$ Individuos e instituciones políticas cuya subjetividad se refuerza con los enlaces -internos a la webde otros artículos sobre los personajes citados, no sobre el "tema" como hace El País.

5 Nos permitimos este adjetivo porque, en nuestra observación a lo largo de estos meses, especialmente en la semana a la que se refieren los artículos analizados aquí, El Mundo ha insistido mucho, más que El País, sobre el evento excepcional de la huelga de padres y madres, en prácticamente todos los artículos de la semana. Sin embargo, esta insistencia que podría llevar a interpretar que muestra el apoyo de El Mundo a las protestas y por ende a entenderla como una crítica al gobierno, en realidad es contrastada por el dato extratextual que hemos obtenido: la periodista autora de este artículo y de los demás sobre educación en este medio en una entrevista nos dijo que había sido la única en asistir a la rueda de prensa convocada por la CEAPA antes de la huelga, y había recogido ese dato de "novedad" que luego habían resaltado otros medios (incluso El País). Al ser la única en hacerlo, el periódico y ella misma seguían sacando partido de esta "noticia", por lo que el subrayar tiene que ver con las rutinas productivas y las estrategias de aparecer como los primeros y los más informados, más que otra cosa.
} 


\section{RESULTADOS: PERSPECTIVAS Y MARCOS DE SENTIDO SOBRE EL ISSUE}

Los análisis realizados nos han proporcionado guías sobre las perspectivas que componen el issue, los relatos y los marcos de sentido usados por los dos periódicos. Como recordábamos al comienzo de este artículo, nuestro análisis ha empezado con la identificación de los actores representados como responsables de los discursos presentes en la información recopilada en el corpus completo (más allá de los artículos analizados aquí). Estos actores son:

1- El Gobierno: representado por el ministro de Educación, José Ignacio Wert y en algunos casos (con presencia minoritaria), por la secretaria de Estado de Educación, Montserrat Gomendio.

2- Las Comunidades Autónomas (CCAA) en cuanto autoridades competentes en materia de educación, especialmente presentes la Consejería de Educación de Madrid, la Consellería de Educación de Galicia, la Consellería de Ensenyament de Catalunya y la Conserjería de Educación de Andalucía.

3- Los profesionales de la Educación: los profesores (Enseñanza Primaria y Secundaria; Universidad) y sus organizaciones (conferencia de Rectores; asociaciones de Directores de Colegios, etc.).

4- Los sindicatos (especialmente Comisiones Obreras, Unión General de Trabajadores, y el Sindicato de Estudiantes).

5- Padres y Madres: a través de sus organizaciones, la CEAPA (mayoritaria en los colegios españoles, con 12.000 asociaciones afiliadas, que representan a 5 millones de familias) y la CONCAPA, la Confederación Católica de Padres de Familia y Padres de Alumnos (reúne las asociaciones de los colegios privados católicos, con 51 federaciones de padres; 3 millones de familias).

6- Los alumnos: testimonios privados y organizaciones estudiantiles (sobre todo el Sindicato de Estudiantes).

7- Los movimientos de la sociedad civil: Soy pública y Yo estudié en la pública; las Plataformas para la Educación de los barrios de Madrid; la FAPA, Francisco Giner de los Ríos.

8- Algunos partidos políticos: PP, PSOE, IU.

Hemos resumido el número de actores, en realidad más amplio, dado que cada partido político y cada sindicato de los aquí mencionados aparece como un actor con objetivos y líneas de acción diferenciadas. Lo mismo cabe decir de los movimientos sociales o de las Comunidades Autónomas. 
Los análisis de elpais.com y elmundo.es, nos han llevado a identificar distintas estrategias enunciativas y diferentes relatos, donde cada medio presenta y articula las perspectivas de los actores para construir los respectivos marcos de sentido.

En síntesis, hemos detectado como fundamentales en los textos de ambos medios sobre el asunto estudiado, "reforma en educación", los siguientes relatos que representan ciertas perspectivas relevantes en el conflicto:

- El problema es la politización. Los que protestan contra las reformas son unos radicales, irresponsables; son manipulados por la izquierda anti-sistema; es una protesta política ${ }^{6}$ impulsada por la oposición. Relato del Partido Popular sobre un antisujeto, quienes protestan, que persigue el objeto de destruir a su adversario político;

- La reforma y los recortes son necesarios y positivos para el sistema educativo, especialmente en una época de crisis; las razones de la protesta son inmotivadas, irracionales y políticas. Relato del ministro Wert y el gobierno sobre el sujeto que persigue un bien para el país, al que se opone un anti-sujeto que carece de racionalidad;

- Los "recortes" responden a un proyecto premeditado, a una voluntad política de destruir la educación pública y gratuita, con vistas a impulsar un modelo elitista para pocos. A ese plan son funcionales la eliminación de las becas de libros y de comedor para los más necesitados, la subida de tasas, la reducción del número de profesores y el aumento de alumnos que merman la calidad de la enseñanza; es un ataque voluntario por parte de sectores políticos afines y por el gobierno. Relato de CEAPA, padres, estudiantes, sindicatos CCOO y UGT, Sindicato de Estudiantes sobre el anti-sujeto cuyo objeto es destruir un bien común, la educación pública;

- Los recortes tienen la finalidad de ahorrar dinero en las contrataciones de profesionales; producen una pérdida de calidad de la enseñanza y sobre todo de puestos de trabajo. Relato de los sindicatos CCOO y UGT y de profesionales de la educación sobre un anti-sujeto que busca reducir el gasto y la calidad en educación y expulsar a trabajadores;

- El problema es la ideología de la derecha. La reforma de la educación es ideológica, propia de un partido conservador y de derechas como el PP, que premia la competitividad, el individualismo, el privilegio, frente a la solidaridad, el apoyo mutuo o la igualdad. Relato de los partidos de izquierdas, PSOE, IU, los sindicatos CCOO y UGT y el Sindicato de Estudiantes sobre un anti-sujeto cuyo objeto es imponer su modelo ideológico al país.

Destacamos que las perspectivas son menores al número de actores, por la coincidencia de varios de estos en sostener un mismo planteamiento, además de que un mismo actor, como el caso de los sindicatos, está presente en más de una perspectiva (como es habitual, tratándose de una huelga). Y que los varios relatos tienden a

\footnotetext{
${ }^{6}$ Estas conclusiones son derivadas también del análisis de los otros artículos de la semana de protestas, incluyendo dos artículos reportados de forma muy similar por las dos cabeceras, sobre las declaraciones del portavoz del PP en el Congreso, que tacha de etarras a los padres y madres ("en mi época las huelgas las convocaban los de Batasuna"). Pese a esta similitud de "contenido", la construcción del asunto por parte de los dos periódicos se diferencia en el paratexto, pues por ejemplo El Mundo da amplio espacio a una noticia de un "asalto" a un colegio concertado católico en Mérida relacionándolo (por el momento en que se publica, y por los tonos en que se presenta -y asumiendo la perspectiva del PP o de los católicos) con los participantes a la huelga.
} 
condensarse en dos macrorrelatos que representan perspectivas opuestas sobre el conflicto entorno al issue:

- macrorrelato de la politización: las reformas en educación son necesarias y positivas (al máximo plantean dificultades para algunos debido a la situación económica); generan protestas únicamente por la voluntad de crear un conflicto político;

- macrorrelato de la posición ideológica: el gobierno se aprovecha de la crisis económica del país para desmantelar el sistema educativo público, en virtud de un modelo elitista que defiende los privilegios de unos pocos.

Nos interesa observar cómo inciden estas perspectivas en la creación de los relatos que conforman los marcos de sentido de cada medio ${ }^{7}$ y si éstos se identifican con la visión de alguno de los actores del conflicto:

- El País: transmite, como hemos apuntado, la idea de una fuerte conflictividad (tijeretazo; Vivan los radicales abajo los ultras; Familias y estudiantes endurecen la protesta contra los recortes; Wert arremete contra los padres que llaman a la huelga) y de una situación dramática para la sociedad. Recoge y hace suyas las perspectivas de ciertas plataformas y organizaciones de la enseñanza (especialmente de la CEAPA y del Sindicato de Estudiantes) y del PSOE (Medio millón de alumnos perderán las ayudas para libros de texto); se insiste en las cifras económicas de la reforma, resumida en "los recortes" (decenas de miles de profesores menos, pérdida de programas de apoyo a los estudiantes, de becas y ayudas para libros de texto y comedor e importantes aumentos del precio de las matrículas universitarias en la mayoría de las comunidades), mientras se dejan al margen, o se alude a ellos sólo en artículos de opinión y editoriales, otros aspectos de la política educativa (como la pérdida de materias necesarias para el desarrollo humano; la reducción de la diversidad lingüística y cultural; la supresión de los comedores escolares; el trasvase forzoso de alumnos a las escuelas privadas, señalados en los discursos de plataformas como Soy Pública y Yo Estudié en la Pública, así como en el blog de la Marea Verde);

- El Mundo: proporciona un marco de conflicto también pero más habitualizado, menos grave y exasperado. Aunque no evita presentar las críticas a las reformas del gobierno, las inserta en un clima general y ordinario de oposición entre organizaciones (sean partidos o sindicatos). En general, se dedica menos espacio y menos peso al asunto. Se acentúa el carácter político de las protestas, aproximándose así a la perspectiva que hemos identificado como propia del PP, dedicando por ejemplo un artículo entero (mientras que El País recoge las mismas declaraciones en otro artículo más general) al fuego cruzado de declaraciones entre PP, Gobierno y PSOE (e IU, Izquierda Plural, etc.).

Concluyendo, a partir de los resultados de nuestros análisis, en respuesta a las preguntas que nos habíamos puesto a final de la segunda parte del texto, sostenemos por un lado que el enfoque teórico elegido, a partir de un issue concreto como objeto de valor de las diferentes perspectivas de los sujetos que se mueven en la EPM,

\footnotetext{
7 Recurriendo una vez más a nuestro análisis de un corpus más vasto, confirmamos que los marcos de sentido que actúan en las webs de los dos periódicos son coherentes, con ciertos matices debidos a las distintas estrategias comerciales, con los de las versiones impresas de los mismos.
} 
es metodológicamente productivo. En los análisis hemos visto cómo es fundamentalmente a partir de sus acciones y de las perspectivas que sostienen como los actores entran como sujetos políticos y discursivos en la EPM, y así están en condiciones de aspirar a hacer valer, mediáticamente, su definición del asunto. Al mismo tiempo, existe una acción de mediación de estas perspectivas y sujetos, de los que algunos son incluidos y otros excluidos, por parte de los medios de información: resulta clara la tendencia de los medios actuales -debido también a las condiciones de producción- a la rapidez, al sensacionalismo, a la simplificación/banalización de los asuntos, reducidos a metáforas conocidas, a slogans y consignas, a valores ideológicos fácilmente reconocibles. Los marcos creados por El País y El Mundo difieren por estrategias comerciales y de organización editorial, además de por la diferenciación ideológica que caracteriza a sus lectores-modelo. Notamos aquí una tendencia a la homogeneización de las noticias, consecuencia de la crisis económica y la mercantilización del mundo de la información y sobre todo a una reducción de las perspectivas y sujetos. Como hemos visto, por un lado se tiende a simplificar en un "uno contra uno" el conflicto sobre el issue; por otro lado, vemos cómo se privilegian los sujetos organizados e institucionalizados: sindicatos mayoritarios, organizaciones consolidadas, partidos, sujetos institucionales que de alguna forma han formado siempre parte del sistema y tiene más facilidades para llegar también al sistema mediático. La prensa generalista tiende a excluir a sujetos concretos, así como las perspectivas no institucionales, más espontaneas, que suelen en cambio caracterizar a los nuevos movimientos sociales (y que en este conflicto se han agrupado en torno a plataformas como Soy Pública o Yo Estudié en la Pública). Hay que decir que el uso de Internet ha sido fundamental en el desarrollo del movimiento de protesta, en la constitución de fuentes de información y de discurso alternativas y ha permitido la aparición de perspectivas e intereses muy diversos. Sin embargo, medios como elpais.com y elmundo.es, si bien observamos a lo largo del tiempo que se apropian en el desarrollo de su discurso de aportaciones de ciertos movimientos en red, raramente los mencionan como fuentes o como actores. Por este motivo no figuran aquí en la relación de las perspectivas visibilizadas por esos medios. En el momento actual podemos decir que los usos de la red sin duda dinamizan y abren la esfera pública, aunque en esta parecen todavía prevalecer los medios mayoritarios y profesionales, que tienden a oscurecer el papel de las plataformas y sitios ciudadanos.

\section{REFERENCIAS BIBLIOGRÁFICAS}

AIMC (Abril 2012-Marzo 2013): Resumen General EGM. Madrid: AIMC.

APM-Asociación de Periodistas de Madrid (2012): Informe anual de la profesión periodistica 2012, Madrid.

ARENDT, Hannah (1974): La condición humana. Barcelona: Seix Barral.

Boczkowski, Pablo J. y Peer, Limor (2011): “The Choice Gap: The Divergent Online News Preferences of Journalists and Consumers" en Journal of Communication 61, pp. 857-876. 
CÁceres Zapatero, María Dolores (2011): “La construcción social de la realidad: el papel de los profesionales en el establecimiento de la agenda temática" en Estudios sobre el mensaje periodístico, 17:2. Madrid: UCM.

Casetti, Francesco y Di Chio, Federico (1991): Cómo analizar un film. Barcelona: Paidós

CosEnZA, Giovanna (2005): Semiotica dei nuovi media. Roma: Laterza.

Curran, James (2010): “The future of journalism” en Journalism Studies, Vol. 11, No 4, Londres: Taylor and Francis.

CurRan , James y Curran y Witschge, Tamara (2010): "Liberal Dreams and the Internet" en Fenton, Natalie (2010): New Media Old News. Journalism and Democracy in the Digital Age. Londres: Sage Publications.

DAhlgren, Peter (2005): "The Internet, Public Spheres, and Political Communication: Dispersion and Deliberation" en Political Communication, 22. Londres: Taylor and Francis, pp. 147-162.

De La Sierra, Susana y Mantini, Marina (2011): Does media policy promote media freedom and independence? The case of Spain, Mediadem Case Study, $7^{\text {th }}$ Frame Programme EU Project.

De LA SIERRA, Susana et al. (2010). Media policies and regulatory practices in a selected set of European countries, the EU and the Council of Europe: The case of Spain, Mediadem Background Information Report, $7^{\text {th }}$ Frame Programme EU Project.

DEWEY, John (2004): La opinión pública y sus problemas. Madrid: Ediciones Morata.

DíAz NosTy, Bernardo (2011): "Los nuevos escenarios de la prensa" en TELOS. Cuadernos de Comunicación e Información, 86. Madrid: Fundación Telefónica.

EnTMAN, Robert (1993): "Framing: Toward Clarification of a Fractured Paradigm", in Journal of Communication, 43, 4, pp. 51-8.

Fenton, Natalie (2010): New Media Old News. Londres: Sage.

Freedman, Des (2010): “The Political Economy of the News Environment" en Fenton, Natalie: New Media Old News. Londres: Sage.

Genette, Gérard (1987): Seuils. Paris: Seuil.

GiLlmor, Dan (2008): We the Media. Grassroots Journalism by the People for the People. O’Reilly Media.

Greimas, Algirdas Julien y Courtés, J. (1979): Sémiotique. Dictionnaire raisonné de la theorie du langage, Paris: Hachette.

Habermas, Jurgen (1989): The Structural Transformation of the Public Sphere: An Inquiry into a Category of Bourgeois Society. Cambridge: Polity.

Jenkins, Henry (2003): "Transmedia Storytelling" en Technology Review. Retrieved December 2

Krause, Sharon R. (2008): Civil Passions: Moral Sentiment and Democratic Deliberation. Princeton: Princeton University Press

Kristeva, Julia (1978): Semiótica. Madrid: Fundamentos

LANG, Gladys Engel y LANG, Kurt (1981): "Watergate. An Exploration of the AgendaBuilding Process", en Wilhoit, G. C. y DeBock, H. (eds): Mass Communication Review Yearbook 2, Beverly Hills, CA: Sage, pp. 447-468

López Hidalgo, A y Mellado Ruiz, C. (2006): "Periodistas atrapados en la Red: rutinas de trabajo y situación laboral” en Estudios sobre el Mensaje Periodiístico. Madrid: UCM, pp. 161-170.

Lorusso, Anna Maria y Violi, Patrizia (2004): Semiotica del testo giornalistico. Roma: Laterza.

MAnetTI, Giovanni (2008): L'enunciazione. Milano: Mondadori. 
Manovich, Lev (2005): El lenguaje de los nuevos medios de comunicación. La imagen en la era digital. Barcelona: Paidós.

MANTINI, Marina (2012): "Movimientos sociales, comunidades virtuales y desarrollo" en Comunicación, Cambio Social y Desarrollo, CIC. Cuadernos de Información y Comunicación, 17. Madrid: UCM, pp. 135-160.

Marres, Noortje Suzanne (2005): No Issue, No Public. Democratic Deficits after the Displacement of Politics. Amsterdam. Institutional Repository of the University of Amsterdam (UvA).

MCChesney, Robert (2012): "Farewell to Journalism" en Journalism Studies, 5-6, Taylor and Francis, pp. 682-694.

McComBs, Maxwell (1996): "Influencia de las noticias sobre nuestras imágenes del mundo" en BRYANT, J. y ZiLlmanN, D. (1996), (v. o. 1994): Los efectos de los medios de comunicación. Investigaciones y teorías. Barcelona: Paidós, pp. 13-34.

- (1985), (v. o. 1975): "La comunicación de masas en las campañas políticas: información, gratificación y persuasión” en Moragas, M. de (eds.). Sociología de la Comunicación de Masas. Estructura, funciones y efectos. Barcelona: Gustavo Gili

MezzA, Michele (2011): Sono le news, bellezza!. Perugia: Donzelli.

Mouffe, Chantal (2007): En torno a lo político. Buenos Aires. Fondo de Cultura Económica

PeÑAMARín, Cristina (2011): "Dialogue between Meaning Systems in Intermedial Texts" en CLCWeb: Comparative Literature and Culture, Volume 13 Issue 3.

- (2008): “¿Hay vida política en el espacio público mediatizado?” en CIC. Cuadernos de Información y Comunicación, 13. Madrid: UCM.

ReIG, Ramón (2011): Los dueños del periodismo. Barcelona: Gedisa.

De SAussure, Ferdinand (2002): Écrits de linguistique générale. Paris: Gallimard.

Tuchmann, Gaye (1999): "La objetividad como ritual estratégico: un análisis de las nociones de objetividad de los periodistas" en CIC. Cuadernos de Información y Comunicación, 4. Madrid: UCM, pp. 199-217.

Weaver, David y Elliot, Swanzy Nimley (1985): "Who sets the Agenda for the Media? A Study of Local Agenda-Setting" en Journalism Quarterly, 62, pp. 87-94.

Wolf, Mauro (1992): Gli effetti sociali dei media. Milano: Bompiani. 


\title{
RESUMEN
}

En este artículo tratamos los resultados de un trabajo semiótico de investigación sobre los discursos informativos relativos a las protestas sobre la reforma educativa en España. La elección de estos contenidos responde al objetivo de dar cuenta de las distintas perspectivas propuestas por los actores involucrados, y consecuentemente de sus narraciones. Al mismo tiempo, se pretende dibujar un mapa del conflicto sobre este asunto "controvertido", donde los marcos de sentido, los puntos de vista son fruto de la lucha para la construcción del mismo llevada a cabo por los actores involucrados.

Palabras clave: semiótica, periodismo, issue, etnografía, información.

\section{The perspective of issue analysis: the case of education in the narratives of mediated public sphere}

\begin{abstract}
This article analyses the findings of a large research work about informational discourses concerning the debate and the protests against educational governmental reforms in Spain. The aim is intercepting and screening the various and different perspectives submitted by actors involved and consequently describing their narratives. At the same time, it is possible identifying points of view, interests and power relationships in the media public sphere, which necessarily match in the representation of issues by the mass media mediation.
\end{abstract}

Keywords: Semiotics, Journalism, Issue, Ethnography, Information.

\section{SOMMARIO}

L'articolo presentato riporta i risultati di un lavoro più ampio di ricerca semiotica sui discorsi dell'informazione concernente le proteste in atto in Spagna sulle riforme in educazione. Lo scopo è indagare le diverse prospettive proposte dagli attori coinvolti in questo tema, e quindi le loro narrazioni sullo stesso. In questo modo è stato possibile arrivare a definire le dinamiche d'interesse e le relazioni di potere in atto nella sfera pubblica contemporanea, che necessariamente intervengono nella definizione dell'issue, attraverso la mediazione dei mass media.

Parole chiave: Semiotica, giornalismo, issue, etnografia, informazione. 